\section{Schilling, Viktor}

H. Baum

Institut für Laboratoriumsmedizin, Mikrobiologie und Blutdepot, Regionale Kliniken Holding RKH GmbH, Ludwigsburg, Deutschland

Lebensdaten Deutscher Mediziner, geboren am 28. August 1883 in Torgau, gestorben am 30. Mai 1960 in Rostock.
Verdienste Internist und Hämatologe; arbeitete 1910-1913 im Hamburger Tropeninstitut und im Ersten Weltkrieg als Hygieniker bei der Armee, ab 1919 als Internist in der Charité in Berlin. Sein Hauptinteresse galt der Hämatologie und hier insbesondere des Einsatzes der morphologischen Differenzierung zur Erkennung von Erkrankungen ( $>$ Hämogramm nach Schilling, \ Zählkammer). 